\title{
DIGITAL TRANSFORMATION OF BUSINESS MODELS - BEST PRACTICE, ENABLERS, AND ROADMAP
}

\author{
DANIEL SCHALLMO* \\ University of Applied Sciences Ulm \\ Prittwitzstrasse 10, 89075 Ulm, Germany \\ schallmo@hs-ulm.de \\ CHRISTOPHER A. WILLIAMS \\ Ulm University, Helmholtzstraße 16 \\ 89081 Ulm, Germany \\ christopher.williams@uni-ulm.de \\ LUKE BOARDMAN \\ University of Applied Sciences Ulm \\ Prittwitzstrasse 10, 89075 Ulm, Germany \\ boardman@mail.hs-ulm.de
}

Published 30 November 2017

\begin{abstract}
The purpose of this paper is to clarify the definition of digital transformation (DT) and to introduce a structured approach with phases, activities and results. Our research is based on a literature review which provides insight into the basic understanding of DT. Examples complete the research and show the practical application of DT. The main findings are that although DT is a widely known concept, an approach for the structured DT of business models is missing. The paper offers a clear definition of the DT of business models and phases for the DT of business models. Moreover, the paper offers examples of enablers and DT.
\end{abstract}

Keywords: Digital transformation; digitisation; business model; business model innovation; enabler; best practices.

\section{${ }^{*}$ Corresponding author.}

This is an Open Access article published by World Scientific Publishing Company. It is distributed under the terms of the Creative Commons Attribution 4.0 (CC-BY) License. Further distribution of this work is permitted, provided the original work is properly cited. 


\section{Introduction}

What do vehicle makers like Rosenbauer, logistics company DB Schenker, compressor manufacturers such as Bauer, elevator producers like ThyssenKrupp, and Hagleitner, a hygiene goods corporation, have in common? They all use the potential of digitisation to offer customers smarter and faster services and actively shape their business model's digital transformation (DT). DT affects all sectors of society, in particular economies. At the same time, DT opens new networking possibilities and enables cooperation between different actors, who, for example, exchange data and thus initiate processes. In this context, the DT of business models plays an essential role because business models' individual elements can be digitally transformed.

DT has been discussed for many years but what is still unaccounted for is a clear definition for the DT of business models, an approach for how to digitally transform business models, which phases and instruments should be considered, and examples of what enablers exist. In our research, we develop a framework for the DT of business models by analysing the existing literature and studying practical examples. We combine two relevant topics: DT and business model (innovation). Our contribution is important for defining the DT of business models within academia and providing a blueprint for how it can be applied in practice.

\section{Theoretical Background}

\section{History of DT}

Although DT is a popular point of discussion at the moment, the ideas of digital products, services, and mediums were already well-understood in the 1990s and 2000s (Auriga, 2016). For example, in the retail industry, mass media advertising campaigns were considered important digital channels with which to reach customers in the 1990s and 2000s, even though purchases were still primarily made inside brick-and-mortar stores, often with cash. From 2000 to 2015, the rise of smart devices and social media platforms led to a drastic sea change in the methods customers used to communicate with businesses, and also the expectations customers had with regards to response times and multi-channel availability. Businesses started to see that they were now able to communicate digitally with their customers on an individual basis, and often in real time. An ever-growing selection of digital payment options such as PayPal also contributed to more and more online commerce and opportunities for web-based points of sale. Nowadays, there is a focus on mobile devices and on creating value for customers by 
leveraging the kinds of personalised customer data that mobile technologies can generate on a massive scale. Businesses are taking advantage of this personalised information and are able to better tailor their products, communications, and interactions to fit customers' specific needs.

\section{Defining DT}

There is currently no commonly accepted definition for the term DT. Moreover, the terms digitalisation and the digitisation are often used interchangeably (BDI and Roland Berger, 2015). Selected definitions in the context of DT are shown in Table 1.

Table 1. Current definitions.

\begin{tabular}{|c|c|}
\hline Author & Definition \\
\hline BMWi (2015) & $\begin{array}{l}\text { Digitisation stands for the complete networking of all sectors of the } \\
\text { economy and society, as well as the ability to collect relevant } \\
\text { information, and to analyse and translate that information into } \\
\text { actions. The changes bring advantages and opportunities, but they } \\
\text { create completely new challenges. }\end{array}$ \\
\hline Bowersox et al. (2005) & $\begin{array}{l}\text { Digital Business Transformation (DBT) is a "process of reinventing a } \\
\text { business to digitise operations and formulate extended supply chain } \\
\text { relationships. The DBT leadership challenge is about reenergizing } \\
\text { businesses that may already be successful to capture the full } \\
\text { potential of information technology across the total supply chain" }\end{array}$ \\
\hline $\begin{array}{l}\text { Westerman et al. } \\
\text { (2011) }\end{array}$ & $\begin{array}{l}\text { "DT - the use of technology to radically improve the performance or } \\
\text { reach of enterprises - is becoming a hot topic for companies } \\
\text { across the globe. Executives in all industries are using digital } \\
\text { advances such as analytics, mobility, social media, and smart } \\
\text { embedded devices - and improving their use of traditional } \\
\text { technologies such as ERP - to change customer relationships, } \\
\text { internal processes, and value propositions." }\end{array}$ \\
\hline Mazzone (2014) & $\begin{array}{l}\text { "DT is the deliberate and ongoing digital evolution of a company, } \\
\text { business model, idea process, or methodology, both strategically } \\
\text { and tactically." }\end{array}$ \\
\hline PwC (2013) & $\begin{array}{l}\text { DT describes the fundamental transformation of the entire business } \\
\text { world through the establishment of new technologies based on the } \\
\text { internet with a fundamental impact on society as a whole. }\end{array}$ \\
\hline $\begin{array}{l}\text { Bouée and Schaible } \\
\text { (2015) }\end{array}$ & $\begin{array}{l}\text { We understand DT as a consistent networking of all sectors of the } \\
\text { economy and adjustment of the players to the new realities of the } \\
\text { digital economy. Decisions in networked systems include data } \\
\text { exchange and analysis, calculation and evaluation of options, as } \\
\text { well as initiation of actions and the introduction of consequences. }\end{array}$ \\
\hline
\end{tabular}


Based on the literature, we propose the following definition of DT for our research:

The DT framework includes the networking of actors such as businesses and customers across all value-added chain segments (BMWi, 2015, p. 3; Bowersox et al., 2005, 22ff.; Bouée and Schaible, 2015, p. 6), and the application of new technologies (PwC, 2013, p. 9; Westerman et al., 2011, p. 5). As such, DT requires skills that involve the extraction and exchange of data as well as the analysis and conversion of that data into actionable information. This information should be used to calculate and evaluate options, in order to enable decisions and/or initiate activities (BMWi, 2015, p. 3; Bouée and Schaible, 2015, p. 6). In order to increase the performance and reach of a company (Westerman et al., 2011, p. 5), DT involves companies, business models, processes, relationships, products, etc. (Bowersox et al., 2005, 22ff.; Mazzone, 2014, p. 8).

\section{Business process reengineering vs. DT}

Some researchers and practitioners might see similarities between Business Process Reengineering (BPR) and DT. In their oft-cited work, Hammer and Champy (1993) provided a definition of BPR. The authors state that BPR is the rethinking and reengineering of business-related processes in order to reduce costs and improve products and services.

Although there are some similarities between BPR and DT, there are some distinct differences between the two approaches as well. According to Proctor (2017), BPR's focus is mainly on automating rule-based systems. Rule-based systems are defined as sets of clearly assigned rule-based (algorithmic) processes which are automated by technologies. Instead of focusing on rule-based processes like BPR does, the main objectives of DT are obtaining new data and using this data to reimagine these old, rule-based processes.

A more data-oriented approach allows for the opportunity to gain new knowledge and in turn reimagine business models and operations. For example, Airbnb turned its attention from processes to data. Airbnb does not own its own physical assets (e.g., hotels). Here is an example of how old, rule-based processes in the hotel industry can be completely reimagined in a data-driven world. The part-time landlords and landladies who own properties in highly sought-after locations and microlease them on Airbnb offer an alternative to hotels and create unique value for guests (Bendor-Samuel, 2017). 
How employees interpret newly acquired know-how and use it to improve decision-making capabilities is what differentiates DT from other fields of study. All of the new data sources create newly formed knowledge sources based on that data. Instead of only making processes more efficient or quicker, which is the aim of automation, DT requires individuals to rethink old processes and reimagine new processes and decisions.

\section{Definition of business model}

One of our contributions to the field of the DT of business models is the following definition (Schallmo, 2013):

A business model is the basic logic of a company that describes what benefits are provided to customers and partners. A business model answers the question of how the provided benefits flow back into the company in the form of revenue. The created value enables a differentiation from competitors, the consolidation of customer relationships, and the achievement of a competitive advantage. A business model involves the following dimensions and elements:

- The customer dimension contains the customer segments, customer channels, and customer relationships.

- The benefit dimension includes products, services, and values.

- The value-added dimension includes the resources, skills, and processes.

- The partner dimension includes the partner, partner channels, and partner relations.

- The financial dimension includes the revenues and expenses.

The objective is to combine the business model elements in such a way that they mutually reinforce each other. This makes it possible to achieve growth and makes imitation by competitors difficult.

\section{Definition of the DT of business models}

Based on the proposed definitions, we define the DT of business models as follows (Schallmo, 2016):

The DT of business models relates to individual business model elements, the entire business model, value-added chains, as well as the networking of different actors in a value-added network. 
The degree of the DT includes the incremental (marginal) as well as the radical (fundamental) change of a business model. The reference unit with regard to the level of novelty is primarily the customer, but a DT can also affect its own business, partners, industry, and competitors.

Within the DT of business models, enabler(s) and technologies (e.g., big data) are used to generate new applications or services (e.g., on-demand prediction). These enablers require skills that enable data collection and exchange as well as the ability to analyse, calculate, and evaluate options. The evaluated options are used to initiate new processes within the business model. The DT of business models is based on an approach with a sequence of tasks and decisions that are related to one another in a logical and temporal context. It affects four target dimensions: time, finance, space, and quality.

\section{Research Questions and Research Design}

\section{Research questions}

In the previous section, a brief review of the literature established our theoretical foundation for DT. To serve as a basis for our Roadmap, we have selected three independent existing approaches to DT. Esser (2016) defines five phases that lay out a development plan for a DT strategy and its implementation. PricewaterhouseCoopers' framework defines six phases of DT (PwC, 2013). Boueé and Schaible (2015) describe a detailed plan for digital transformation that is specifically designed to prepare for the digital future.

Although these approaches make valuable contributions, they do not completely cover the DT of business models and do not specify the DT's application. In our contribution, we initiate the DT of business models and develop a Roadmap including several phases.

Based on the problem described and current understanding, we will answer the following research questions:

- What does a structured approach to the DT of business models look like?

- What types of phases, activities, and results are relevant?

- Which enablers (e.g., sensors, big data, etc.) and which applications are relevant?

- What examples exist for the DT of business models and what are the best practices in this field? 


\section{Research design}

We applied case study methods to our literature review because this methodology is desirable for describing and analysing relevant cases in which grounded-theory can be developed (Benbasat et al., 1987; Eisenhardt, 1989; Kromrey, 2013; Stake, 1995; Yin, 1994).

We analysed existing definitions, approaches, and examples of the DT of business models. We conducted the literature review to gain insight into current research in DT and developed a Roadmap for the DT of business models, including examples.

\section{Approach to the DT of Business Models}

\section{Roadmap}

A Roadmap is given here based on the presented approaches to DT and based on existing theories about business model innovation (see Bucherer, 2011; Rusnjak, 2014; Schallmo, 2013, 2014; Thomas, 2014), the Roadmap for the DT of business models is explained as follows:

- Digital Reality: In this phase, Digital Reality, the company's existing business model is sketched along with a value-added analysis related to stakeholders and a survey of customer requirements. This provides an understanding of the Digital Reality for this company in different areas.

- Digital Ambition: Based on the Digital Reality, objectives with regards to DT are defined. These objectives relate to time, finances, space, and quality. Digital Ambition postulates which objectives should be considered for the business model and its elements. Subsequently, objectives and business model dimensions are prioritised.

- Digital Potential: Within this Digital Potential phase, best practices and enablers for the DT are established. This serves as a starting point in terms of Digital Potential and the design of a future digital business model. For this purpose, different options are derived for each business model element and combined logically.

- Digital Fit: The Digital Fit phase looks at options for the design of the digital business model, which are evaluated to determine Digital Fit with the existing business model. This ensures that one fulfils customer requirements and that business objectives are achieved. The evaluated combinations are then prioritised.

- Digital Implementation: Digital Implementation includes the finalisation and implementation of the digital business model. The various combinations of 


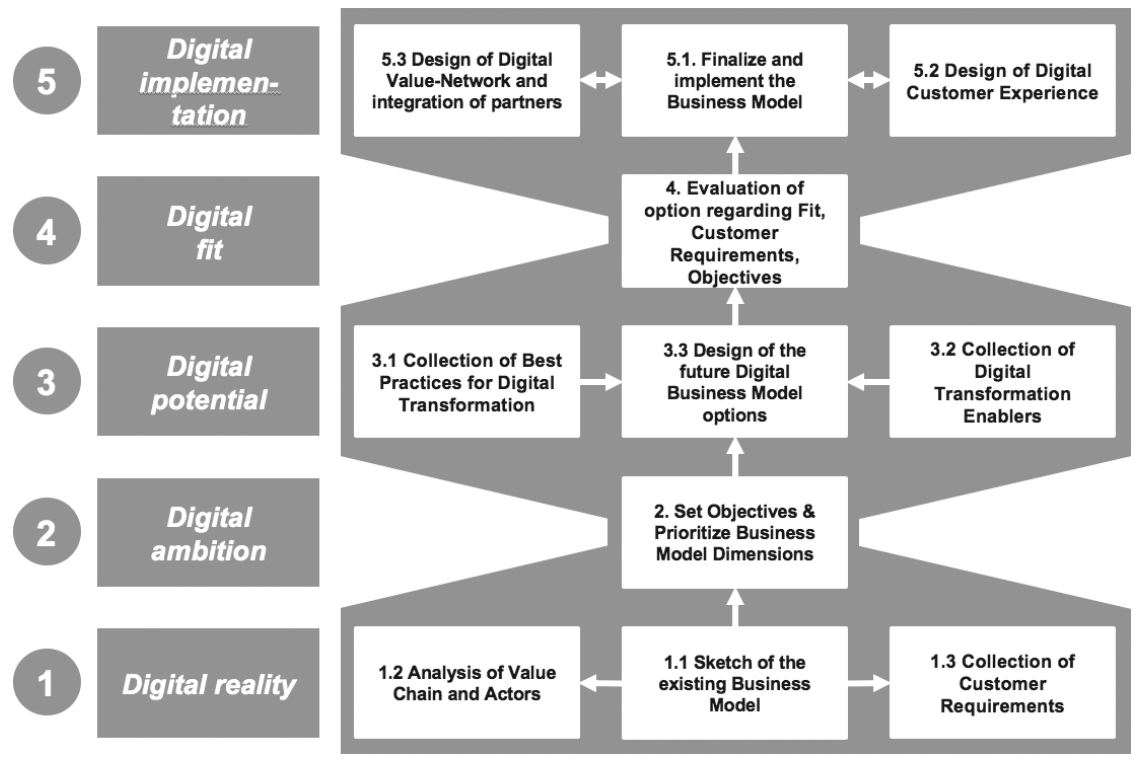

Fig. 1. Roadmap for DT (Schallmo, 2016, p. 23).

options are further pursued within a digital implementation framework. The Digital Implementation also includes the design of a digital customer experience and digital value-creation network that describe integration with partners. In addition, resources and capabilities are also identified in this phase.

Figure 1 represents the Roadmap to the DT of business models with the various phases and activities. The phases are explained further below, each with its specific objectives and questions. Subsequent activities along with each of their instruments are also shown. Selected activities are illustrated by case studies.

\section{Enabler}

Enablers serve to allow applications or services to be used for the DT of the business model. Four categories for enablers and applications/services are detailed below:

- Digital Data: The collection, processing, and analysis of digitised data to facilitate and improve predictions and decisions.

- Automation: The combination of classical artificial intelligence technologies that enables autonomous work and self-organising systems. This reduces error rates, increases speed, and makes it possible to reduce operating costs. 


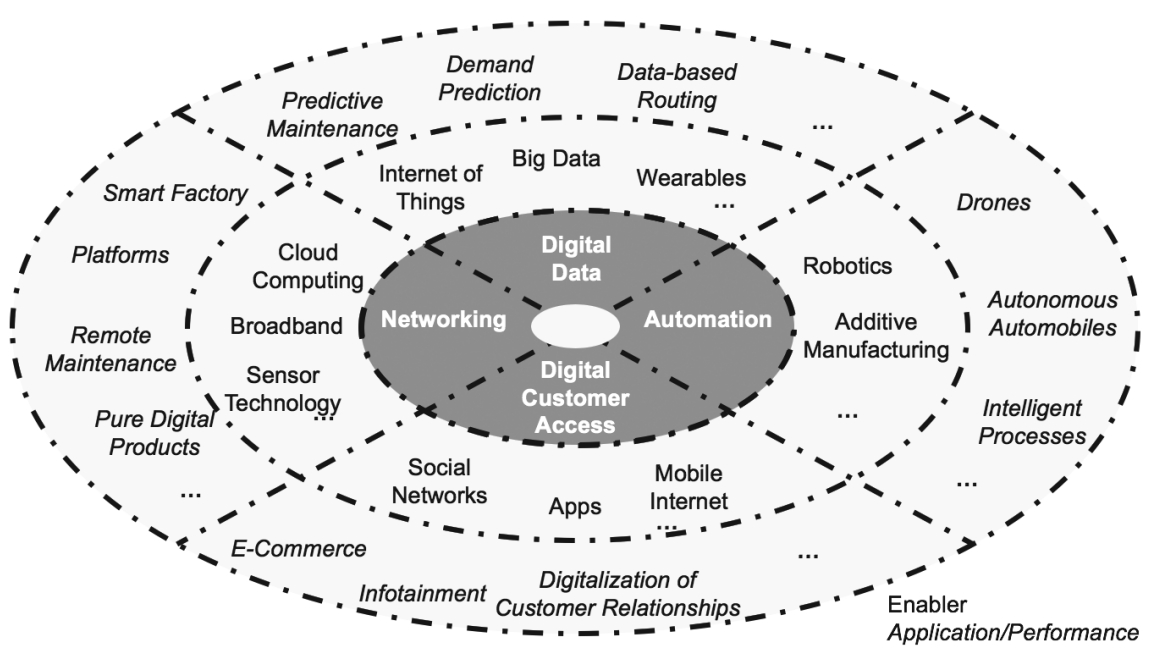

Fig. 2. Digital radar with enablers and applications (Boueé and Schaible, 2015).

- Digital Customer Access: The mobile internet enables direct access to the client, who are thus provided with high levels of transparency and new services.

- Networking: Mobile or wired networking of the entire value-added chain via high speed broadband telecommunications allows for the synchronisation of supply chains, which leads to a reduction in production times and innovation cycles.

Enablers are listed with their applications/services in a digital radar, which is shown in Fig. 2.

The Digital radar can supplement more enablers and applications/services as needed. The following is an example of the additive manufacturing of bionic aircraft components. Additive manufacturing can be used analogously for the printing of spare parts for engines (Knabel, 2015; Flugrevue, 2016). Airbus installed a bionic-shaped bracket in an A350 test aircraft in July of 2014 and flight tests were successful. It is a component which was "printed" (sintered) with titanium powder and it has the same specifications regarding function and strength as a conventional component. Advantages include:

- Less material and weight (30\% lighter)

- Subsequent reduction of fuel consumption

- Increased inventory flexibility, as Airbus can "print" spare parts on the spot according to original specifications without depending on large manufacturing facilities or waiting on shipments. 


\section{Best Practices for the DT of Business Models}

\section{ThyssenKrupp}

ThyssenKrupp is a German industrial group with different divisions. The Elevator Technology division produces passenger and freight elevators as well as escalators for office buildings, residential buildings, hotels, airports, shopping centres, and other facilities. In addition to the sale and installation of elevators and escalators, maintenance, repair, and modernisation services are also offered (ThyssenKrupp, 2016a).

\section{Initial situation \& problem definition}

ThyssenKrupp's old business model mainly focused on the manufacturing of elevators, installing them, and carrying out maintenance as needed. An increasing number of tall buildings in major cities led to an increased demand for highperformance elevators. Furthermore, customers and users demanded superior elevator reliability. In addition, several already-installed elevators posed a risk to users due to maintenance backlogs (ThyssenKrupp, 2016b; Wetzel, 2014). Additionally, ThyssenKrupp's competitors began to offer elevator maintenance service packages, which is a high-margin offering compared to product sales (Dispan, 2007: 22; Odermatt and Kressbach, 2011).

\section{Objective \& solution approach}

The objective of ThyssenKrupp's elevator business was to reduce the duration of their elevators' outages by identifying causes of potential failure in a predictive manner. This would ultimately allow for faster maintenance and shorter repair times. To address this concern, they created the MAX, Elevator Monitoring System.

The timely identification of potential causes of outages requires a real-time flow of information which provides key insights into an elevator's current status. To accomplish this, they outfitted ThyssenKrupp elevator components, such as drive motors, elevator doors, and elevator shafts, with sensors. These sensors collect information such as the cabin speed and motor temperature. The information obtained is then evaluated with the help of predictive analytics and provided to employees, who are responsible for maintenance and technology. These employees now receive warning alerts as well as maintenance guidance and recommendations.

These changes allowed ThyssenKrupp to proactively carry out maintenance work and with foresight, thus reducing elevator downtime. In addition, costs, resources, and maintenance planning were improved (CGI, 2016). 


\section{Results}

ThyssenKrupp's MAX Elevator Monitoring System is an example of a maintenance-oriented digitisation initiative. MAX collects relevant technical and mechanical information through sensors to reduce maintenance backlogs and improve ThyssenKrupp's overall maintenance services. Put simply, information that was being ignored before is now being collected and utilised to provide value to customers and create profit for ThyssenKrupp - a textbook example of the DT of a business model.

DT is a continual process. One could also imagine other opportunities for DT which ThyssenKrupp could implement. For example, an interactive screen/billboard could be offered in select models of elevators. These touch screens could add value to a wide swath of stakeholders. The interactive elevator billboard could be used by ThyssenKrupp to collect customer satisfaction feedback or the interactive elevator billboard space could be leased or sold outright to end users or third-party advertising agencies. End users could leverage the interactive elevator billboard space to increase company awareness or collect employee feedback on certain company events or decisions, while third party advertisers could use the screen to serve highly-targeted ads to a captive audience.

ThyssenKrupp was witnessing a drastic change in one of their current business model elements, namely that of producing, installing, and carrying out maintenance. The customer maintenance requirements were changing and ThyssenKrupp needed to come up with a solution. The sole purpose of MAX is to gather and take advantage of data and utilise modern predictive analytics to better evaluate and predict maintenance issues.

The proposed interactive elevator billboard space could address another opportunity to add value; namely workplace communication and a chance to introduce a new media channel and marketing platform into an otherwise barren environment. Effective maintenance services are an obvious priority add-on for a major elevator manufacturer like ThyssenKrupp but an in-elevator touch screen digitisation initiative could also be valuable. The idle-time spent riding in an elevator could be seen as a golden opportunity to broadcast information to or collect information from elevator riders.

ThyssenKrupp's Max system increased profitability by offering a premium maintenance add-on service which promises to decrease maintenance backlogs.

The proposed interactive elevator billboard space could provide an additional revenue stream via one-time sales or third party leasing agreements. Alternatively, advertising revenue from the screens could be used to subsidise the initial list price of the elevator for builders and contractors, allowing ThyssenKrupp to position its 
products at more competitive price points while maintaining healthy margins visà-vis their competitors.

ThyssenKrupp's final decision to prioritise the MAX system probably stemmed from the realisation that their in-house maintenance know-how was not being fully utilised. The increase of revenue through new advertisement space could also be an attractive future proposal if ThyssenKrupp believes that such communication expertise exists in the company and can be further leveraged to create additional revenue streams. Comparing the two examples, ThyssenKrupp's MAX maintenance system could be seen as the more pressing need, given their core competencies.

\section{Application to digital reality}

ThyssenKrupp digitally transformed their business model by developing an innovative maintenance management system. ThyssenKrupp's MAX system created a data-driven maintenance system which created new benefits for their customers and in turn generated a new revenue stream. The following sections will apply our Digital Reality analysis to ThyssenKrupp's MAX system and compare it to a theoretical, potential alternative which they could pursue but until now have not — an in-elevator touchscreen billboard.

\section{ThyssenKrupp's customer dimension}

ThyssenKrupp's maintenance-oriented customer dimension in their business model was digitally transformed by their MAX system. ThyssenKrupp's customer requirements were becoming more demanding and with the MAX system, customers were willing to pay more for the increased value to the customer segment element. The MAX system provided clear communication with regards to maintenance repairs and improved their customer relations.

The MAX system introduced an innovative data-driven digital initiative that spoke directly to their customers' and ThyssenKrupp's maintenance departments. Although the MAX system included additional costs for their customers, the improved long-term operation, shorter downtimes, and increased elevator reliability more than returned value.

The interactive elevator billboard takes advantage of an underutilised space in the elevators and creates a new customer channel. This form of advertisement could create a unique customer relations platform and reach customers who would be shown commercials and notices, and who could then provide invaluable insights through their interaction with the media displayed on the screen. 


\section{ThyssenKrupp's benefit dimension}

The enhanced transparency with regards to the maintenance requirements provided benefits for all stakeholders. ThyssenKrupp recognised it was essential to create a new digitally driven process but the real benefit for both ThyssenKrupp and their customers was the access to data allowing for real-time maintenance alerts.

With regards to a touch panel, elevator riders are presented with an opportunity to provide personal feedback. The touchscreen itself is a relatively uncomplicated technology and its development and installation should deliver the benefit of revenue generating advertising or gathering personal feedback.

\section{ThyssenKrupp's value-creation dimension}

The data and capabilities (i.e., resources) for such real-time maintenance alerts were always available but there were not any processes within ThyssenKrupp's business model that specifically took advantage of these resources. Once ThyssenKrupp realised the importance and value of such a maintenance system, it was clear that the development of the MAX system would be able to fulfil this value proposition. The data gathered and simultaneous delivered to both the internal and external stakeholders created tremendous value.

ThyssenKrupp would probably possess the internal capabilities to develop their own interactive elevator billboard space but the development could also be handed over to other external stakeholders. Once the space is created, the process of creating content could be handed off to marketing departments.

\section{ThyssenKrupp's partner dimension}

ThyssenKrupp's partners are an important part of the business model and to better integrate the partners into their business model, the value of ThyssenKrupp's maintenance services needed to be communicated. The MAX system was able to deliver this communication, which in turn improved the relations between ThyssenKrupp and their partners.

The partners' involved in the development of an interactive elevator billboard space would depend on who delivers the actual content. Again, ThyssenKrupp could use this space to obtain feedback about the overall elevator experience but third-party companies could use the space to communicate to their own demographics. The initial development of the touch screen platform would probably also benefit from external software development and consulting.

\section{ThyssenKrupp's financial dimension}

The decision to develop either a data-driven maintenance system like the MAX system or an interactive screen/billboard ultimately depends on the potential 
revenue and expenses. The MAX system could potentially have a better long-term outlook with regards to revenue. The importance of an innovative maintenance system might outweigh the potential additional revenue stream of an interactive screen/billboard. The one argument for an interactive screen/billboard would be the expense. The MAX system involved considerable financial investment but an interactive screen/billboard would probably require a smaller investment, considering that the underlying technologies are ubiquitous, the software architecture is relatively simple, and additional sensors/sensor networking is not required.

An interactive elevator billboard space would have a positive effect on the financial dimension inasmuch as it would provide an additional revenue stream either to ThyssenKrupp or their partners. For example, ThyssenKrupp could require a rental fee for the space or simply include a surcharge in the purchase price of the elevator.

\section{Contributions}

The contribution of this research is to initiate the discussion of the DT of business models by providing a concise definition, examples, and enablers. Based on this, an integrated, five-phase approach for how to successfully execute a DT was presented. This addresses an existing research gap regarding the DT of business models, which is linked to innovation management in general.

\section{Practical Implications}

Senior managers and business developers will gain from our findings by acquiring a clear definition, examples, and enablers of the DT of business models. The fivestep Roadmap enables companies to take advantage of DT's potential (e.g., sensors, big data) and reimagine their business model. By applying the Roadmap, companies are able to optimise their current business model and create a distinct competitive advantage.

\section{Limitations}

The aim of this paper is to report our research results on the DT of business models. The reader should bear in mind that due to practical constraints, the results may not be fully generalisable. Furthermore, some aspects (e.g., the broad application of our approach in several industries) need to be further investigated. Therefore, we recommend interviews with practitioners and longitudinal studies in other circumstances in order to establish a greater understanding of DT. 


\section{Recommendations for Further Research}

Further research regarding the impact of the DT of business models would be worthwhile. For example, it would be interesting to create a knowledge building community where researchers and practitioners can compare experiences gained from our approach in different industries and company sizes. Another possible area of future research would be to investigate the role of DT within innovation management, particularly in the field of business model innovation. Lastly, future studies need to establish the quantifiable benefits of DT.

\section{References}

Auriga (2016). Digital Transformation: History, Present, and Future Trends. Retrieved June 15, 2017, from https://auriga.com/blog/digital-transformation-history-presentand-future-trends/.

BDI and Roland Berger (2015). Analysen zur Studie - Die Digitale Transformation der Industrie, Roland Berger Strategy Consultans und Bundesverband der Deutschen Industrie e.V.

Benbasat, I, DK Goldstein and M Mead (1987). The case research strategy in studies of information systems. MIS Quarterly, 11(3), 369-386.

Bendor-Samuel, P (2017). The power of digital transformation in a data-driven world. Retrieved October 14, 2017, from https://www.forbes.com/sites/peterbendorsamuel/2017/07/21/the-power-of-digital-transformation-in-a-data-driven-world/ \#4e1837393f2c.

Boueé, C and S Schaible (2015). Die Digitale Transformation der Industrie. Studie: Roland Berger und BDI.

Bowersox, DJ, DJ Closs and RW Drayer (2005). The digital transformation: Technology and beyond. Supply Chain Management Review, 9(1), 22-29.

Bucherer, E (2011). Business Model Innovation - Guidelines for a Structured Approach. Doctoral thesis, St. Gallen.

BMWi (2015). Industrie 4.0 und Digitale Wirtschaft - Impulse für Wachstum, Beschäftigung und Innovation, Berlin: Bundesministerium für Wirtschaft und Energie.

CGI (2016). Predictive Maintenance, [online] https://www.de.cgi.com/casestudy/thyssenkrupp-elevator-predictive-maintenance [20.04.2016].

Dispan, J (2006). Aufzüge und Fahrtreppen-eine Branche im Wandel. IG Metall.

Esser, M (2016). Chancen und Herausforderungen durch Digitale Transformation. [online] http://www.strategy-transformation.com/digitale-transformation-verstehen/ [02.02.2016].

Eisenhardt, KM (1989). Building theories from case study research. Academy of Management Review, 14(4), 532-550. 
Flugrevue (2016). Bionisches und herkömmliches Bauteil, [online] http://www.flugrevue. de/zivilluftfahrt/flugzeuge/airbus-a350-fliegt-erstmals-mit-3d-gedrucktem-bauteil/ 581076 [13.04.2016].

Hammer, M and J Champy (1993). Reeingineering the Corporation. New York: Harper Business.

Knabel, J (2015). Airbus über 3D-Druck in der Luftfahrt [online] http://3druck.com/ industrie/airbus-ueber-3d-druck-der-luftfahrt-4919624/ [02.02.2016].

Kromrey, H (2013). Empirische Sozialforschung: Modelle und Methoden der standardisierten Datenerhebung und Datenauswertung, Vol. 1040. Berlin: Springer-Verlag.

Mazzone, DM (2014). Digital or Death: Digital Transformation - The Only Choice for Business to Survive Smash and Conquer. (1st ed.). Mississauga, Ontario: Smashbox Consulting Inc.

Odermatt, P and M Kressbach (2011). Liftkonzerne schröpfen Mieter und Eigentümer. [online] http://www.srf.ch/sendungen/kassensturz-espresso/themen/wohnen/liftkonzerne-schroepfen-mieter-und-eigentuemer [20.04.2016].

Proctor, J (2017). Digital Transformation vs. Business Process Reengineering (BPR). Retrieved October 11, 2017, from http://content.inteqgroup.com/digital-transformation-vs-business-process-reengineering.

PwC (2013). Digitale Transformation - der größte Wandel seit der Industriellen Revolution. Frankfurt: PricewaterhouseCoopers.

Rusnjak, A (2014). Entrepreneurial Business Modeling: Definitionen-VorgehensmodellFramework-Werkzeuge-Perspektiven. Berlin: Springer-Verlag.

Schallmo, DR (2013). Geschäftsmodelle erfolgreich entwickeln und implementieren: Mit Aufgaben und Kontrollfragen. Berlin: Springer-Verlag.

Schallmo, DR (2014). Vorgehensmodell der geschäftsmodell-innovation-bestehende ansätze, phasen, aktivitäten und ergebnise. In Kompendium Geschäftsmodell-Innovation, pp. 51-74. Wiesbaden: Springer Fachmedien.

Schallmo, DR (2016). Jetzt Digital Transformieren: So Gelingt die Erfolgreiche Digitale Transformation Ihres Geschäftsmodells. Berlin: Springer-Verlag.

Stake, RE (1995). The Art of Case Study Research. USA: Sage.

ThyssenKrupp (2016a). Homepage von ThyssenKrupp Elevator, [online] http://www. thyssenkrupp-elevator.com/Unternehmen.3.0.html [20.04.2016].

ThyssenKrupp (2016b). ThyssenKrupp liefert Mobilitätslösungen für weltweite Wahrzeichen [online] http://www.thyssenkrupp-elevator.com/Eintrag-anzeigen.104.0. html?\&cHash=4b80049df1e8243dcd8a7e31a8ec5c92\&tx_ttnews\%5Btt_news\% $5 \mathrm{D}=564$ [20.04.2016].

Thomas, DKMJ (2014). Design und entwicklung der business model-innovation. In Kompendium Geschäftsmodell-Innovation: Grundlagen, aktuelle Ansätze und Fallbeispiele zur erfolgreichen Geschäftsmodell-Innovation, DR Schallmo (Ed.). New York: Springer-Verlag.

Westerman, G, C Calméjane, D Bonnet, P Ferraris and A McAfee (2011). Digital transformation: A roadmap for billion-dollar organizations. MIT Center for Digital Business and Capgemini Consulting, 1-68. 
Wetzel, D (2014). Deutschlands Fahrstühle werden zum Risiko. Retrieved March 17, 2016, from https://www.welt.de/wirtschaft/article128523956/Deutschlands-Fahrstuehlewerden-zum-Risiko.html.

Yin, RK (1994). Discovering the future of the case study method in evaluation research. Evaluation Practice, 15(3), 283-290. 